\title{
Dinâmica da florística e da estrutura horizontal em um fragmento de Floresta Ombrófila Mista Montana
}

\author{
Mailson ROIK ${ }^{1 *}$, Afonso FIGUEIREDO FILHO ${ }^{1}$, Tiago GRESPAN ${ }^{2}$, \\ Thiago Floriani STEPKA ${ }^{2}$, Rodrigo Otávio Veiga de MIRANDA ${ }^{3}$
}

\author{
${ }^{1}$ Universidade Federal do Paraná, Curitiba, PR, Brasil \\ ${ }^{2}$ Universidade Estadual do Centro-Oeste, Lages, SC, Brasil. \\ ${ }^{3}$ Universidade Federal de Uberlândia, Uberlândia, MG, Brasil. \\ *E-mail: mailsonroik@gmail.com
}

Recebido em janeiro/2019; Aceito em março/2019.

\begin{abstract}
RESUMO: Este trabalho objetivou analisar as alterações na composição florística e estrutura horizontal em um fragmento de Floresta Ombrófila Mista, localizado na Floresta Nacional (FLONA) de Irati, Paraná, Brasil, assim como compará-lo quanto à florística e estrutura de outros fragmentos florestais localizados em FLONAs da região sul do país. Todos os indivíduos com diâmetro à altura do peito maior ou igual a $10 \mathrm{~cm}(\mathrm{DAP} \geq 10 \mathrm{~cm})$ foram identificados e mensurados ao longo de nove anos. A floresta apresentou elevada riqueza de espécies ao longo do período de monitoramento e pequenas alterações em relação a sua composição florística e estrutura horizontal. As divergências florístico-estruturais entre os fragmentos utilizados para comparação com o presente estudo se devem principalmente à grande heterogeneidade intrínseca a esta fitofisionomia, como também ao aumento da dissimilaridade em função do distanciamento geográfico.
\end{abstract}

Palavras-chave: análise multivariada; composição florística; fitossociologia; Floresta com Araucária.

\section{Dynamics of floristic and horizontal structure in a fragment of Montane Mixed Ombrophylous Forest}

\begin{abstract}
The aim of this research was to analyze the changes on the floristic composition and horizontal structure in an Araucaria Forest fragment, located in the Irati National Forest (FLONA), Paraná State, Brazil, as well as comparing it to the floristic and structure of other forest fragments located in FLONAs of the southern region of the country. All the individuals with diameter at breast height equal or larger than $10 \mathrm{~cm}$ (DBH $\geq 10$ $\mathrm{cm})$ were identified and measured for nine years. The forest presented a high number of species during the monitoring period and few changes in floristic composition and horizontal structure. The floristic-structural divergences among the fragments used for comparison with the present study are mainly due to the great heterogeneity intrinsic to this phytophysiognomy, as well as to the increase of dissimilarity due to geographic distance.
\end{abstract}

Keywords: Araucaria forest; floristic composition; multivariate analysis; phytosociology.

\section{INTRODUÇÃO}

A Floresta com Araucária, classificada como Floresta Ombrófila Mista - FOM (IBGE, 2012), representa uma das principais formações florestais da região Sul do Brasil, contendo em sua composição florística representantes das floras tropical (afro-brasileira) e temperada (austro-brasileira), marcada fisionomicamente por elementos Coniferales e Laurales, com a presença marcante de Araucaria angustifolia (Bertol.) Kuntze. A distribuição geográfica desta fitofisionomia está associada, principalmente, à elevadas altitudes e baixas temperaturas médias anuais.

Outrora, $175.000 \mathrm{~km}^{2}$ da região Sul do Brasil era originalmente ocupada por Floresta Ombrófila Mista. Atualmente, diferentes cenários revelam o desflorestamento causado pela extração de madeira, pela queima e conversão das áreas para fins agrícolas, pecuária, reflorestamento com espécies introduzidas, entre outras causas (PROBIO, 2007; MMA, 2010).

Considerando a grande importância ambiental, econômica e social que a Floresta Ombrófila Mista representa para a região Sul do país, são fundamentais o estudo e conhecimento de suas características no que tange à florística, estrutura, funcionamento, fisionomia, dinâmica, distribuição e relações ambientais. Nesse sentido, o estudo sobre a florística e estrutura da comunidade vegetal são imprescindíveis para a definição de estratégias de manejo e conservação dos remanescentes existentes.

Tais características podem ser obtidas pelo levantamento fitossociológico contínuo. Este tipo de levantamento permite estudar e acompanhar a alteração da floresta ao longo dos anos. A maneira mais adequada de avaliar a composição florística, a estrutura e a dinâmica de uma floresta de forma integral, é monitorá-la sistematicamente e por longos períodos. A metodologia conhecida mais indicada para tal finalidade é a instalação e medição de parcelas permanentes. Goldsmith; Harrison (1976) afirmaram que mudanças na vegetação em longos períodos são melhores estudadas com o uso de parcelas permanentes ou de transectos permanentes.

Muitos autores se dedicaram ao estudo dos fragmentos de Floresta Ombrófila Mista existentes na região Sul do Brasil, 
dentre os quais destacam-se: Durigan (1999), Watzlawick et al. (2005), Moscovich (2006), Figueiredo Filho et al. (2010), Mognon et al. (2012), Sawczuk et al. (2012), Silva et al. (2012), Higuchi et al. (2013), Ebling et al. (2014), Cubas et al. (2016), Martins et al. (2017), entre outros.

Diante do exposto, o presente estudo teve como objetivo analisar as alterações referentes à composição florística e estrutura horizontal em um fragmento de Floresta Ombrófila Mista, localizado na Floresta Nacional de Irati, Paraná, Brasil, monitorado ao longo de um período de nove anos. Ainda, compará-lo quanto à florística e estrutura com outros fragmentos florestais localizados em FLONAs na região sul do país.

\section{MATERIAL E MÉTODOS}

\subsection{Caracterização da área de estudo}

A pesquisa foi realizada em um fragmento de Floresta Ombrófila Mista localizado na Floresta Nacional (FLONA) de Irati, Paraná, Brasil, a qual está situada no segundo planalto paranaense, no âmbito dos municípios de Fernandes Pinheiro e Teixeira Soares, integrantes da microrregião Colonial de Irati (Figura 1). Localiza-se entre a margem direita do rio das Antas e esquerda do rio Imbituvão, pertencentes à bacia hidrográfica do rio Tibagi, a uma altitude média de 820 metros.

Baseando-se na classificação de Köppen, o clima da região é do tipo $\mathrm{Cfb}$ - Subtropical Úmido Mesotérmico, caracterizado por verões frescos, geadas severas e frequentes e sem estação seca. Apresenta estações climáticas bem definidas, com chuvas distribuídas durante todo o ano. A precipitação média mensal é de $194 \mathrm{~mm}$, média anual de $1605,7 \mathrm{~mm}$ e a umidade relativa média mensal do ar é de $79,5 \%$. A temperatura média anual é de $18^{\circ} \mathrm{C}$, com a mínima anual de $-2^{\circ} \mathrm{C}$ e a máxima de $32^{\circ} \mathrm{C}$. O limiar médio das temperaturas de Irati varia, aproximadamente, entre 13 e $23,5^{\circ} \mathrm{C}$ (SIMEPAR, 2018).

Predominam na área quatro classes de solo, sendo elas: Latossolo Vermelho distrófico típico (LVd), Cambissolo Háplico Ta distrófico típico (CXvdt), Cambissolo Háplico Ta distrófico léptico (CXvdl) e Cambissolo Háplico alítico típico (CXal).

\subsection{Origem dos dados}

Foram utilizados dados de 25 parcelas permanentes instaladas em 2002 em um fragmento de Floresta Ombrófila Mista com 1.272,9 ha. Cada parcela permanente de 1 ha (100 $\mathrm{m} \times 100 \mathrm{~m}$ ) é subdividida em quatro subparcelas de 0,25 ha $(50 \mathrm{~m}$ x $50 \mathrm{~m})$. Com o objetivo de facilitar a numeração e o mapeamento das árvores (distâncias X, Y), cada subparcela é subdividida em cinco faixas de controle de $10 \mathrm{~m}$ x $50 \mathrm{~m}(0,05$ ha). No ano 2002 foi realizada a primeira medição das parcelas permanentes ( $25 \mathrm{ha})$, adotando um limite de inclusão de $10 \mathrm{~cm}$ de DAP (diâmetro à altura do peito - 1,30 m do solo). Nos anos de 2005, 2008 e 2011 foram realizadas as remedições, totalizando assim, nove anos de monitoramento da dinâmica da floresta. Nessas ocasiões foram computadas as árvores mortas e as que ingressaram no sistema.

\subsection{Identificação botânica}

Todas as árvores presentes nas parcelas permanentes, com diâmetro à altura do peito maior ou igual a $10 \mathrm{~cm}$ (DAP $\geq 10$ $\mathrm{cm}$ ) foram identificadas. Foram coletadas amostras de material botânico de todas as espécies ocorrentes na área amostrada. O material coletado foi herborizado e incorporado ao Herbário da UNICENTRO (HUCO). A identificação das espécies foi realizada por consulta a especialistas, pesquisa bibliográfica e por comparação com material do acervo disponível no Herbário HUCO. As espécies foram agrupadas em famílias, seguindo o sistema proposto pelo Angiosperm Phylogeny Group IV (APG et al., 2016).

\subsection{Composição florística e suficiência amostral}

A análise florística e suas alterações foram realizadas com base nas 25 parcelas permanentes inventariadas durante 0 período de nove anos. As faixas de controle de $500 \mathrm{~m}^{2}$, que constituem cada uma das parcelas permanentes, foram mantidas devido sua importância na análise da frequência das espécies. Logo, o banco de dados empregado para análise da composição florística foi constituído de uma parcela com área de 25 hectares, subdividida em 500 faixas de controle de 500 $\mathrm{m}^{2}$, avaliadas nos anos de 2002, 2005, 2008 e 2011.

A análise da alteração na composição florística foi realizada pela presença ou ausência de cada espécie nas remedições. Foram avaliadas e quantificadas todas as espécies, gêneros e famílias presentes na área amostrada em cada ano de monitoramento do fragmento.

Com o objetivo de auxiliar a avaliação da maturidade da floresta, cada espécie teve um grupo ecológico associado, possibilitando relacionar a similaridade das espécies em função de seus grupos correspondentes, bem como ao predomínio de cada grupo. Os grupos ecológicos definidos para cada espécie foram baseados em consultas bibliográficas: Lorenzi (2002), Vaccaro (2002), Carvalho (2003), Carvalho (2006), Moscovich (2006), Carvalho (2008), Sawczuk et al. (2009) e Kersten et al. (2015).

Avaliou-se a frequência do número de espécies e do número de indivíduos pertencentes a cada grupo ecológico, bem como da dominância de cada grupo em cada período de avaliação. Com isso, foi determinada a importância, em relação ao número de espécies, indivíduos e área basal, correspondente a cada grupo ecológico.

A suficiência amostral foi verificada pela curva de acumulação de espécies obtida pelo método de aleatorização, com 1.000 permutações, apresentada juntamente aos intervalos de confiança da riqueza florística para as unidades amostrais.

\subsection{Análise da estrutura horizontal}

A estrutura horizontal foi caracterizada pelos parâmetros fitossociológicos de densidade, frequência e dominância das espécies, bem como do valor de importância, (Equações 1 a 7), tendo-se como foco, sobretudo, as mudanças ocorridas entre as medições de 2002 e 2011.

$$
\begin{aligned}
& \mathrm{DA}=\frac{\mathrm{n}_{\mathrm{i}}}{\mathrm{A}} \\
& \mathrm{DR}=\frac{\mathrm{n}_{\mathrm{i}}}{\mathrm{N}} \cdot 100 \\
& \mathrm{FA}_{\mathrm{i}} \frac{\mathrm{p}_{\mathrm{i}}}{\mathrm{P}} \cdot 100 \\
& \mathrm{~F}=\frac{\mathrm{FA}_{\mathrm{i}}}{\sum \mathrm{FA}_{\mathrm{i}}} \cdot 100 \\
& \mathrm{DoA}=\frac{\mathrm{g}_{\mathrm{i}}}{\mathrm{A}} \\
& \mathrm{DoR}=\frac{\mathrm{g}_{\mathrm{i}}}{\sum \mathrm{g}_{\mathrm{i}}} \\
& \mathrm{VI}=\left(\frac{\mathrm{DR}+\mathrm{FR}+\mathrm{Do}}{3}\right)
\end{aligned}
$$

em que: $D A=$ densidade absoluta (ind.ha ${ }^{-1}$ ); $D R=$ densidade relativa (\%); $n_{i}=$ número de indivíduos da $i$-ésima espécie; $N=$ número total de indivíduos; $A$ = área (ha); $F A=$ frequência absoluta (\%); $F R=$ 
frequência relativa $(\%) ; p_{i}=$ número de unidades amostrais em que ocorre a $i$-ésima espécie; $P=$ número total de unidades amostrais; $D o A=$ dominância absoluta $\left(\mathrm{m}^{2} \cdot \mathrm{ha}^{-1}\right) ; D o R=$ dominância relativa $(\%) ; g_{i}=$ área transversal da $i$-ésima espécie $\left(\mathrm{m}^{2}\right) ; V I=$ valor de importância $(0-100 \%)$.

Nos resultados apresentados nesta pesquisa, tendo em vista limitações de espaço constam apenas as espécies que apresentaram valor de importância (VI) superior a 1\%. A metodologia utilizada para a determinação das taxas de ingresso e mortalidade, apresentadas na discussão dos resultados estão descritas em Roik (2012).

\subsection{Classificação e Ordenação}

Foram compiladas da literatura científica listas florísticas de remanescentes de Floresta Ombrófila Mista do Paraná, Santa Catarina e do Rio Grande do Sul (Figura 1). As espécies arborescentes passaram por uma revisão detalhada acerca de sinonímias botânicas.

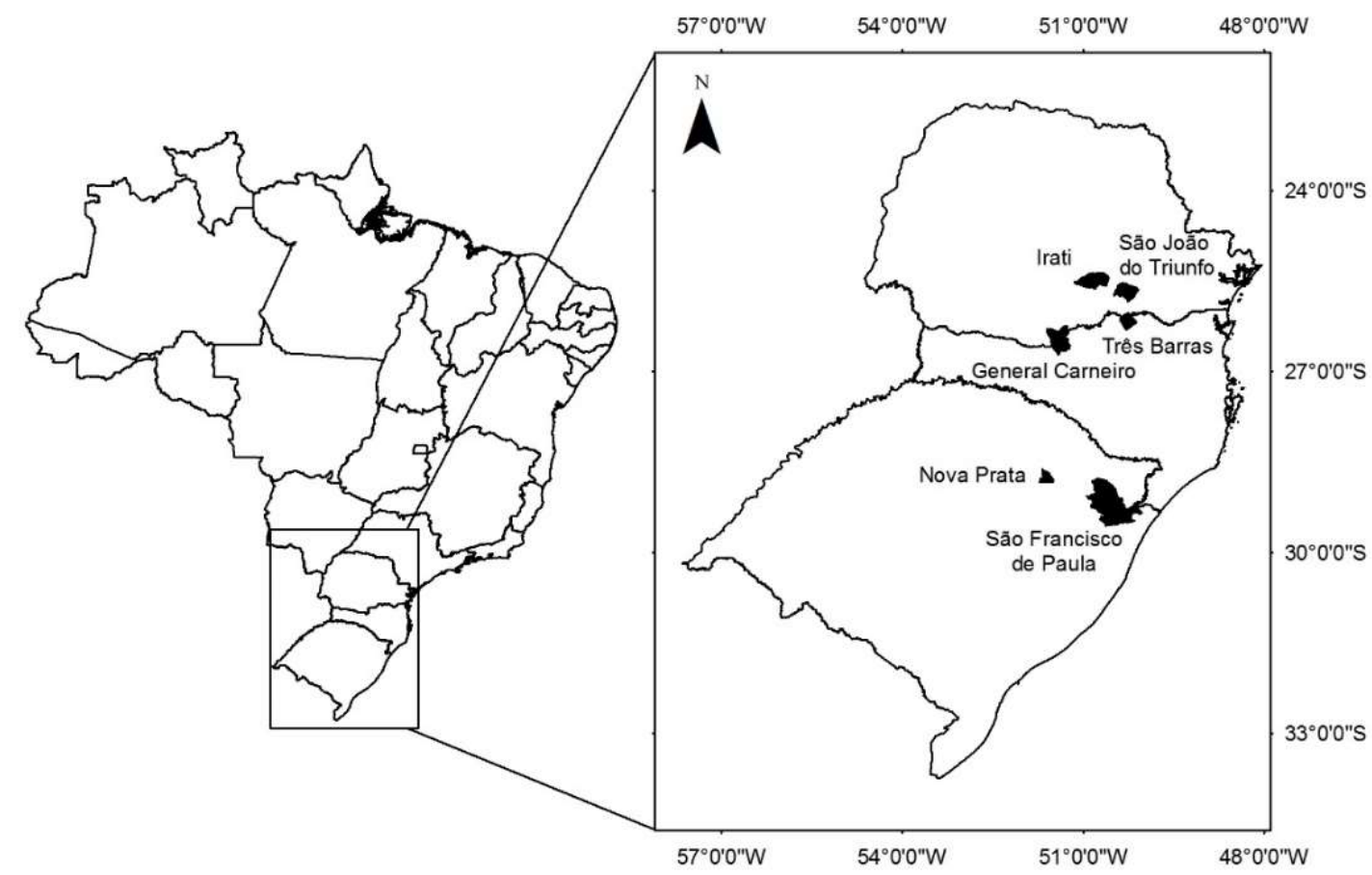

Figura 1. Localização dos municípios onde os estudos em remanescentes de Floresta Ombrófila Mista utilizados para comparação foram desenvolvidos.

Figure 1. Location of the municipalities where the studies in remnants of Mixed Ombrophilous Forest used for comparison were developed.

Objetivando verificar a similaridade florística entre o presente estudo e os demais selecionados, foram aplicados dois métodos multivariados a partir de uma matriz de abundância. O primeiro corresponde a uma Análise de Agrupamento, onde empregou-se a distância de Bray-Curtis, por esta ser recomendada para dados quantitativos e também por não considerar duplas ausências (LEGENDRE; LEGENDRE, 2012). O método de agrupamento utilizado foi a média de grupo (UPGMA - Unweighted Pair Group Average Method). O segundo método, aplicado com o objetivo de detectar padrões florísticos e estimar o comprimento de gradiente por meio do primeiro eixo de ordenação, corresponde à Análise de Correspondência Retificada (DCA), adotando-se o algoritmo de Hill com a correção de tendência com partição em 26 segmentos para recálculo com 999 interações (LEGENDRE; LEGENDRE, 2012).

Foi aplicado também o teste de Mantel (MANTEL, 1967) para verificar a relação entre a localização geográfica e a composição florística, ou seja, verificar se a distribuição de espécies ocorre ao acaso ao longo das regiões amostradas ou se a variável localização espacial apresenta efeito sobre tal composição. O referido teste, cuja hipótese nula corresponde à ausência de padrão espacial, avalia a correlação entre duas matrizes de dissimilaridade, neste caso uma matriz de distância espacial (euclidiana) e outra de distância florística (Bray-Curts).

Todas as análises foram processadas no programa estatístico R (R DEVELOPMENT CORE TEAM, 2015), versão 3.2.3 com a utilização do pacote Vegan (OKSANEN et al., 2018). Ressalta-se que, para as análises multivariadas, foi empregado a matriz de abundância composta pelas espécies com Valor de Cobertura (VC) maior que 1, pois as espécies com baixa ocorrência contribuem pouco na estrutura da comunidade e enviesam os resultados das análises.

\section{RESULTADOS}

\subsection{Alterações na composição florística}

$\mathrm{Na}$ área amostrada foram encontradas 580,8 e 560,9 árvores por hectare, respectivamente em 2002 e 2011. Durante os nove anos de monitoramento foram registradas 124 espécies arbóreas, 84 gêneros e 42 famílias botânicas. Houve, ainda, a ocorrência de 25 indivíduos que foram medidos, porém, morreram antes de serem devidamente identificados. A composição florística, número de indivíduos por espécie e a classificação das espécies em seus respectivos grupos ecológicos são apresentados na Tabela 1 . 
Tabela 1. Composição florística e grupos ecológicos em um fragmento de Floresta Ombrófila Mista na FLONA de Irati, Paraná, no período de monitoramento (2002-2011).

Table 1. Floristic composition and ecological groups in a fragment of Mixed Ombrophylous Forest in the FLONA of Irati, Paraná, during the monitoring period (2002-2011).

\begin{tabular}{|c|c|c|c|c|c|}
\hline \multirow{2}{*}{ Família } & \multirow{2}{*}{ Nome Científico } & \multirow{2}{*}{ Nome Comum } & \multicolumn{2}{|c|}{ N.ha ${ }^{-1}$} & \multirow{2}{*}{$\mathrm{GE}^{*}$} \\
\hline & & & 2002 & 2011 & \\
\hline Anacardiaceae & Lithraea molleoides (Vell.) Engl. & Aroeira-branca & 1,24 & 0,84 & $\mathrm{Pi}^{4}$ \\
\hline \multirow[t]{2}{*}{ Annonaceae } & Annona rugulosa (Schltdl.) H.Rainer & Ariticum-de-porco & 0,04 & 0 & $\mathrm{Si}^{9}$ \\
\hline & Annona sylvatica A.St.-Hil. & Ariticum & 0,08 & 0,16 & $\mathrm{St}^{4}$ \\
\hline \multirow[t]{4}{*}{ Aquifoliaceae } & Ilex brevicuspis Reissek & Voadeira & 0,36 & 0,40 & $\mathrm{Si}^{4}$ \\
\hline & Ilex dumosa Reissek & Cauninha & 1,60 & 1,12 & $\mathrm{Si}^{4}$ \\
\hline & Ilex paraguariensis A. St.-Hil. & Erva-mate & 60,20 & 52,12 & $\mathrm{Si}^{4}$ \\
\hline & Ilex theezans Mart. ex Reissek & Caúna & 12,68 & 10,52 & $\mathrm{Si}^{4}$ \\
\hline Araliaceae & Schefflera morototoni (Aubl.) Maguire et al. & Mandiocão & 1,32 & 1,08 & $\mathrm{St}^{1}$ \\
\hline Araucariaceae & Araucaria angustifolia (Bertol.) Kuntze & Araucária & 42,12 & 42,32 & $\mathrm{Cl}^{8}$ \\
\hline Arecaceae & Syagrus romanzoffiana (Cham.) Glassman & Palmeira & 18,00 & 18,08 & $\mathrm{Si}^{2}$ \\
\hline Asparagaceae & Cordyline spectabilis Kunth \& Bouché & Uvarana & 0 & 0,08 & $\mathrm{Pi}^{9}$ \\
\hline \multirow[t]{7}{*}{ Asteraceae } & Baccharis semisserata DC. & Tupichava & 0 & 0,04 & $\mathrm{Pi}^{9}$ \\
\hline & Gochnatia polymorpha (Less.) Cabrera & Cambará & 0,04 & 0 & $\mathrm{Pi}^{7}$ \\
\hline & Piptocarpha angustifolia Dusén ex Malme & Vassourão-branco & 2,24 & 1,84 & $\mathrm{Pi}^{7}$ \\
\hline & Piptocarpha axillaris (Less.) Baker & Vassourão-cambará & 0,60 & 1,00 & $\mathrm{Pi}^{7}$ \\
\hline & Raulinoreitzia leptophlebia (B.L.Rob.) R.M.King \& H.Rob. & Vassourão-de-brinco & 0 & 0,04 & $\mathrm{Pi}^{9}$ \\
\hline & Vernonanthura discolor (Spreng.) H. Rob. & Vassourão-preto & 2,00 & 1,88 & $\mathrm{Pi}^{7}$ \\
\hline & Vernonanthura petiolaris (DC.) H. Rob. & Vassourão & 4,28 & 1,92 & $\mathrm{Pi}^{7}$ \\
\hline \multirow[t]{2}{*}{ Bignoniaceae } & Handroanthus albus (Cham.) Mattos & Ipê-amarelo & 0,04 & 0,04 & $\mathrm{St}^{4}$ \\
\hline & Jacaranda micrantha Cham. & Caroba & 3,16 & 3,40 & $\mathrm{Si}^{4}$ \\
\hline Canellaceae & Cinnamodendron dinisii Schwacke & Pimenteira & 14,36 & 11,96 & $\mathrm{Pi}^{7}$ \\
\hline Cardiopteridaceae & Citronella paniculata (Mart.) R.A.Howard & Congonha & 0,04 & 0 & $\mathrm{St}^{9}$ \\
\hline \multirow[t]{2}{*}{ Celastraceae } & Maytenus grandiflora Reissek & Espinheira-santa-falsa & 0,04 & 0,20 & $\mathrm{Cl}^{9}$ \\
\hline & Maytenus officinalis Mabb. & Espinheira-santa & 0,20 & 0,36 & $\mathrm{Cl}^{9}$ \\
\hline Clethraceae & Clethra scabra Pers. & Carne-de-vaca & 5,60 & 4,24 & $\mathrm{Pi}^{7}$ \\
\hline \multirow[t]{2}{*}{ Cunoniaceae } & Lamanonia ternata Vell. & Guaraperê & 0,20 & 0,20 & $\mathrm{Si}^{2}$ \\
\hline & Weinmannia paulliniifolia Pohl ex Ser. & Gramimunha & 0 & 0 & $\mathrm{Si}^{7}$ \\
\hline Elaeocarpaceae & Sloanea hirsuta (Schott) Planch. ex Benth. & Sapopema & 4,92 & 4,08 & $\mathrm{St}^{9}$ \\
\hline Erythroxylaceae & Erythroxylum deciduum A. St.-Hil. & Cocão & 0,04 & 0,04 & $\mathrm{Pi}^{7}$ \\
\hline \multirow[t]{3}{*}{ Euphorbiaceae } & Actinostemon concolor (Spreng.) Müll.Arg. & Laranjinha-do-mato & 0,08 & 0,04 & $\mathrm{Cl}^{4}$ \\
\hline & Sapium glandulosum (L.) Morong & Leiteiro & 1,08 & 1,08 & $\mathrm{Pi}^{4}$ \\
\hline & Sebastiania commersoniana (Baill.) L.B.Sm. \& Downs & Branquilho & 0,20 & 0,28 & $\mathrm{Si}^{2}$ \\
\hline \multirow[t]{10}{*}{ Fabaceae } & Albizia edwallii (Hoehne) Barneby \& J.W.Grimes & Farinha-seca & 0,28 & 0,28 & $\mathrm{Si}^{7}$ \\
\hline & Anadenanthera colubrina (Vell.) Brenan & Angico-branco & 0,20 & 0,20 & $\mathrm{Si}^{9}$ \\
\hline & Cassia leptophylla Vogel & Canafistula & 0,76 & 0,72 & $\mathrm{Si}^{7}$ \\
\hline & Dalbergia brasiliensis Vogel & Jacarandá & 9,84 & 8,92 & $\mathrm{Si}^{7}$ \\
\hline & Inga virescens Benth. & Ingá & 1,56 & 1,64 & $\mathrm{Si}^{9}$ \\
\hline & Lonchocarpus muehlbergianus Hassl. & Timbó & 0,04 & 0,08 & $\mathrm{Pi}^{9}$ \\
\hline & Machaerium stipitatum (DC.) Vogel & Sapuva & 3,52 & 2,68 & $\mathrm{Si}^{7}$ \\
\hline & Mimosa scabrella Benth. & Bracatinga & 1,08 & 1,44 & $\mathrm{Pi}^{6}$ \\
\hline & Ormosia arborea (Vell.) Harms & Coronheira & 0,08 & 0,08 & $\mathrm{Si}^{7}$ \\
\hline & Parapiptadenia rigida (Benth.) Brenan & Monjoleiro & 0,80 & 1,04 & $\mathrm{Si}^{4}$ \\
\hline Lamiaceae & Aegiphila integrifolia (Jacq.) Moldenke & Pau-de-gaiola & 0,24 & 0,20 & $\mathrm{Pi}^{7}$ \\
\hline & Vitex megapotamica (Spreng.) Moldenke & Tarumã & 0,08 & 0,08 & $\mathrm{St}^{4}$ \\
\hline Lauraceae & Cinnamomum amoenum (Nees \& Mart.) Kosterm. & Canela-alho & 0,40 & 0,32 & $\mathrm{St}^{9}$ \\
\hline & Cinnamomum glaziovii (Mez) Kostem. & Canela-papagaio & 0,08 & 0,04 & $\mathrm{Cl}^{6}$ \\
\hline & Cinnamomum sellowianum (Nees \& Mart.) Kosterm. & Canela-branca & 2,56 & 2,32 & $\mathrm{St}^{7}$ \\
\hline & Cryptocarya aschersoniana $\mathrm{Mez}$ & Canela-fogo & 0,32 & 0,36 & $\mathrm{Cl}^{1}$ \\
\hline & Nectandra grandiflora Nees & Canela-amarela & 37,72 & 33,68 & $\mathrm{Si}^{4}$ \\
\hline & Nectandra megapotamica (Spreng.) Mez & Canela-imbuia & 17,16 & 17,60 & $\mathrm{Si}^{4}$ \\
\hline & Ocotea corymbosa (Meisn.) Mez & Canela-pimenta 2 & 1,40 & 2,04 & $\mathrm{St}^{7}$ \\
\hline & Ocotea diospyrifolia (Meisn.) Mez & Canela-pimenta & 9,24 & 9,08 & $\mathrm{St}^{4}$ \\
\hline & Ocotea indecora $(\mathrm{Schott}) \mathrm{Mez}$ & Canela-preta & 0,60 & 0,68 & $\mathrm{St}^{7}$ \\
\hline & Ocotea odorifera (Vell.) Rohwer & Sassafrás & 51,96 & 52,88 & $\mathrm{St}^{9}$ \\
\hline & Ocotea porosa (Nees \& Mart.) Barroso & Imbuia & 19,32 & 19,00 & $\mathrm{Cl}^{2}$ \\
\hline & Ocotea puberula (Rich.) Nees & Canela-guaicá & 13,96 & 12,68 & $\mathrm{Si}^{4}$ \\
\hline & Ocotea pulchella (Nees \& Mart.) Mez & Canela-lageana & 0 & 0,08 & $\mathrm{Si}^{4}$ \\
\hline & Persea major (Meisn.) L.E.Kopp & Pau-de-andrade & 0,76 & 0,64 & $\mathrm{St}^{9}$ \\
\hline Loganiaceae & Strychnos brasiliensis (Spreng.) Mart. & Esporão-de-galo & 0,04 & 0,08 & $\mathrm{Pi}^{1}$ \\
\hline Lythraceae & Lafoensia pacari A.St.-Hil. & Dedaleiro & 1,00 & 0,88 & $\mathrm{Si}^{7}$ \\
\hline Malvaceae & Luehea divaricata Mart. \& Zucc. & Açoita-cavalo & 0,76 & 0,48 & $\mathrm{St}^{2}$ \\
\hline Meliaceae & Cabralea canjerana (Vell.) Mart. & Canjerana & 0,56 & 0,64 & $\mathrm{St}^{3}$ \\
\hline & Cedrela fissilis Vell. & Cedro & 15,44 & 14,88 & $\mathrm{Pi}^{6}$ \\
\hline & Cedrela lilloi C.DC. & Cedrilho & 0,04 & 0,04 & $\mathrm{St}^{9}$ \\
\hline & Trichilia elegans A.Juss. & Pimenteira-arbustiva & 0 & 0,04 & $\mathrm{Cl}^{4}$ \\
\hline
\end{tabular}




\begin{tabular}{|c|c|c|c|c|c|}
\hline Moraceae & $\begin{array}{l}\text { Ficus enormis Mart. ex Miq. } \\
\text { Sorocea bonplandii (Baill.) W.C.Burger et al. }\end{array}$ & $\begin{array}{l}\text { Figueira } \\
\text { Cincho }\end{array}$ & $\begin{array}{l}0,24 \\
0,04\end{array}$ & $\begin{array}{l}0,20 \\
0,04\end{array}$ & $\begin{array}{r}\mathrm{St}^{9} \\
\mathrm{Si}^{9} \\
\end{array}$ \\
\hline \multirow[t]{3}{*}{ Primulaceae } & Myrsine coriacea (Sw.) R.Br. ex Roem. \& Schult. & Capororoca & 0,28 & 0,40 & $\mathrm{Si}^{4}$ \\
\hline & Myrsine guianensis (Aubl.) Kuntze & Capororoca-vermelha & 0 & 0,04 & $\mathrm{Si}^{4}$ \\
\hline & Myrsine umbellata Mart. & Capororocão & 23,28 & 16,72 & $\mathrm{Si}^{4}$ \\
\hline \multirow[t]{18}{*}{ Myrtaceae } & Blepharocalyx salicifolius (Kunth) O.Berg & Murta & 0 & 0,08 & $\mathrm{St}^{3}$ \\
\hline & Campomanesia guazumifolia (Cambess.) O.Berg & Sete-capote & 0,08 & 0,08 & $\mathrm{St}^{9}$ \\
\hline & Campomanesia xanthocarpa (Mart.) O.Berg & Guabiroba & 6,08 & 6,44 & $\mathrm{St}^{3}$ \\
\hline & Curitiba prismatica (D.Legrand) Salywon \& Landrum & Murteira & 4,40 & 5,24 & $\mathrm{Si}^{9}$ \\
\hline & Eugenia involucrata DC. & Cerejeira & 5,76 & 8,12 & $\mathrm{Cl}^{4}$ \\
\hline & Eugenia pluriflora DC. & Guamirim-abacate & 0,20 & 0,12 & $\mathrm{Cl}^{9}$ \\
\hline & Eugenia pyriformis Cambess. & Uvaia & 0,16 & 0,20 & $\mathrm{Si}^{4}$ \\
\hline & Eugenia uniflora $\mathrm{L}$. & Pitanga & 0,36 & 0,20 & $\mathrm{Si}^{4}$ \\
\hline & Gomidesia affinis (Cambess.) D. Legrand & Perta-goela & 0 & 0,04 & $\mathrm{Si}^{7}$ \\
\hline & Myrceugenia miersiana (Gardner) D. Legrand \& Kausel & Caingá-do-graúdo & 0,04 & 0,04 & $\mathrm{Cl}^{4}$ \\
\hline & Myrcia guianensis (Aubl.) DC. & Guamirim-vermelho & 0,08 & 0,20 & $\mathrm{Cl}^{9}$ \\
\hline & Myrcia hebepetala DC. & Caingá & 9,52 & 11,80 & $\mathrm{St}^{9}$ \\
\hline & Myrcia lajeana D. Legrand & Guamirim-cascudo & 0,08 & 0,40 & $\mathrm{Si}^{7}$ \\
\hline & Myrcia splendens (Sw.) DC. & Guamirim-preto & 8,88 & 7,96 & $\mathrm{Pi}^{9}$ \\
\hline & Myrciaria delicatula (DC.) O.Berg & Araçá-do-mato & 1,24 & 1,48 & $\mathrm{Cl}^{4}$ \\
\hline & Myrciaria floribunda (H.West ex Willd.) O.Berg & Cambuí & 6,28 & 9,56 & $\mathrm{Cl}^{4}$ \\
\hline & Myrciaria tenella (DC.) O. Berg & Guamirim-ferro & 0 & 0,24 & $\mathrm{Cl}^{4}$ \\
\hline & Plinia cauliflora (Mart.) Kausel & Jaboticabeira & 1,56 & 1,56 & $\mathrm{St}^{7}$ \\
\hline N.I. Morta & N.I. Morta & N.I. Morta & 0,72 & 0 & - \\
\hline Picramniaceae & Picramnia parvifolia Engl. & Pau-amargo & 0,20 & 0,20 & $\mathrm{St}^{4}$ \\
\hline Proteaceae & Roupala montana Aubl. & Carvalho & 1,00 & 0,84 & $\mathrm{Cl}^{4}$ \\
\hline Quillajaceae & Quillaja brasiliensis (A. St.-Hil. \& Tul.) Mart. & Saboneteira & 0,24 & 0,24 & $\mathrm{Pi}^{4}$ \\
\hline Rosaceae & Prunus myrtifolia (L.) Urb. & Pessegueiro-bravo & 13,20 & 10,28 & $\mathrm{Si}^{5}$ \\
\hline \multirow[t]{4}{*}{ Rubiaceae } & Coussarea contracta (Walp.) Müll.Arg. & Cinzeiro-preto & 19,88 & 26,16 & $\mathrm{Pi}^{9}$ \\
\hline & Psychotria vellosiana Benth. & Jasmim-verdadeiro & 5,16 & 5,96 & $\mathrm{St}^{7}$ \\
\hline & Randia ferox (Cham. \& Schltdl.) DC. & Limão-do-mato & 0,08 & 0,04 & $\mathrm{Pi}^{7}$ \\
\hline & Rudgea jasminoides (Cham.) Müll.Arg. & Véu-de-noiva & 0,16 & 0,76 & $\mathrm{St}^{7}$ \\
\hline \multirow[t]{3}{*}{ Rutaceae } & Citrus sinensis (L.) Osbeck. & Laranjeira & 0,08 & 0,12 & $\mathrm{Pi}^{9}$ \\
\hline & Zanthoxylum kleinii (R.S.Cowan) P.G. Waterman & Juvevê & 0,48 & 0,48 & $\mathrm{Si}^{4}$ \\
\hline & Zanthoxylum rhoifolium Lam. & Mamica-de-cadela & 1,28 & 1,04 & $\mathrm{Si}^{3}$ \\
\hline \multirow[t]{7}{*}{ Salicaceae } & Casearia decandra Jacq. & Guaçatunga-branca & 35,40 & 31,32 & $\mathrm{Si}^{4}$ \\
\hline & Casearia gossypiosperma Briq. & Espeteiro & 0,04 & 0,04 & $\mathrm{Si}^{7}$ \\
\hline & Casearia lasiophylla Eichler & Guaçatunga-da-graúda & 1,52 & 2,32 & $\mathrm{Si}^{7}$ \\
\hline & Casearia obliqua Spreng. & Guaçatunga-vermelha & 5,20 & 5,80 & $\mathrm{Si}^{7}$ \\
\hline & Casearia sylvestris Sw. & Guaçatunga-preta & 12,28 & 14,44 & $\mathrm{Si}^{9}$ \\
\hline & Prockia crucis P.Browne ex L. & Cambroé & 0,24 & 0,40 & $\mathrm{St}^{7}$ \\
\hline & Xylosma pseudosalzmanii Sleumer & Sucareiro & 0,72 & 0,84 & $\mathrm{Si}^{1}$ \\
\hline \multirow[t]{5}{*}{ Sapindaceae } & Allophylus edulis (A.St.-Hil. et al.) Hieron. ex Niederl. & Vacum & 4,88 & 6,36 & $\mathrm{Si}^{1}$ \\
\hline & Allophylus petiolulatus Radlk. & Vacum-de-folha-larga & 1,04 & 1,68 & $\mathrm{St}^{9}$ \\
\hline & Cupania vernalis Cambess. & Cuvatã & 1,84 & 1,92 & $\mathrm{St}^{3}$ \\
\hline & Diatenopteryx sorbifolia Radlk. & Maria-preta & 1,60 & 2,28 & $\mathrm{St}^{7}$ \\
\hline & Matayba elaeagnoides Radlk. & Miguel-pintado & 18,08 & 14,96 & $\mathrm{St}^{3}$ \\
\hline \multirow[t]{2}{*}{ Sapotaceae } & Chrysophyllum gonocarpum (Mart. \& Eichler ex Miq.) Engl. & Guatambu & 3,68 & 4,04 & $\mathrm{St}^{7}$ \\
\hline & Chrysophyllum marginatum (Hook. \& Arn.) Radlk. & Guatambu-leite & 1,16 & 1,32 & $\mathrm{St}^{4}$ \\
\hline Simaroubaceae & Picrasma crenata (Vell.) Engl. & Tenente-josé & 2,24 & 2,48 & $\mathrm{St}^{1}$ \\
\hline \multirow{3}{*}{ Solanaceae } & Solanum bullatum Vell. & Fumo-bravo & 0,08 & 0,08 & $\mathrm{Pi}^{9}$ \\
\hline & Solanum pseudoquina A.St.-Hil. & Juazeiro & 0,04 & 0,16 & $\mathrm{Pi}^{4}$ \\
\hline & Solanum sanctaecatharinae Dunal & Cuvitinga & 0,36 & 0,32 & $\mathrm{Pi}^{4}$ \\
\hline Styracaceae & Styrax leprosus Hook. \& Arn. & Canela-raposa & 6,24 & 4,00 & $\mathrm{St}^{5}$ \\
\hline \multirow[t]{3}{*}{ Symplocaceae } & Symplocos tenuifolia Brand. & Maria-mole & 0,04 & 0,12 & $\mathrm{Pi}^{9}$ \\
\hline & Symplocos tetrandra Mart. & Sete-sangria & 0,08 & 0,04 & $\mathrm{St}^{7}$ \\
\hline & Symplocos uniflora (Pohl) Benth. & Maria-mole 2 & 0 & 0,04 & $\mathrm{Si}^{2}$ \\
\hline Theaceae & Laplacea fruticosa (Schrad.) Kobuski & Santa-Rita & 1,80 & 1,12 & $\mathrm{Pi}^{9}$ \\
\hline \multirow[t]{2}{*}{ Winteraceae } & Drimys angustifolia Miers & Cataia 2 & 0 & 0,04 & $\mathrm{Si}^{9}$ \\
\hline & Drimys brasiliensis Miers & Cataia & 2,60 & 2,32 & $\mathrm{Si}^{7}$ \\
\hline 42 & 124 & & 580,8 & 560,9 & \\
\hline
\end{tabular}

${ }^{*} \mathrm{GE}$ = Grupo ecológico; $\mathrm{Pi}$ = pioneira; $\mathrm{Si}$ = secundária inicial; $\mathrm{St}=$ secundária tardia; $\mathrm{Cl}=$ climácica; ${ }^{1}$ Vaccaro (2002); ${ }^{2}$ Carvalho $(2003) ;{ }^{3} \mathrm{Carvalho}(2006) ;$ ${ }^{4}$ Moscovich (2006); ${ }^{5}$ Carvalho (2008); ${ }^{6}$ Lorenzi (2002); ${ }^{7}$ Sawczuk et al. (2012); ${ }^{8}$ Kersten et al. (2015) ${ }^{9}$ classificação sugerida pelo autor.

Pela análise da curva de acumulação (Figura 2), observase uma tendência à estabilização, principalmente após os 15 mil $\mathrm{m}^{2}$ inventariados, com a redução do intervalo de confiança, demostrando que a amostragem foi adequada para a caracterização florística da área.
Durante os nove anos de monitoramento do fragmento observou-se o recrutamento de onze espécies, sendo elas: Baccharis semisserata, Blepharocalyx salicifolius, Cordyline spectabilis, Drimys angustifolia, Gomidesia affinis, Myrciaria tenella, Myrsine guianensis, Ocotea pulchella, Raulinoreitzia leptophlebia, Symplocos uniflora e Trichilia elegans. Com 
isso, ocorreu o ingresso da família Asparagaceae no fragmento, representada pela espécie $C$. spectabilis.

No mesmo período, três espécies egressaram: Citronella paniculata, Gochnatia polymorpha e Annona rugulosa. Assim, a família Cardiopteridaceae foi suprimida do fragmento, pois a espécie $C$. paniculata era a única representante desta família. A espécie Weinmannia paulliniifolia ingressou no ano de 2008, porém não foi encontrado nenhum indivíduo dessa espécie na medição seguinte.

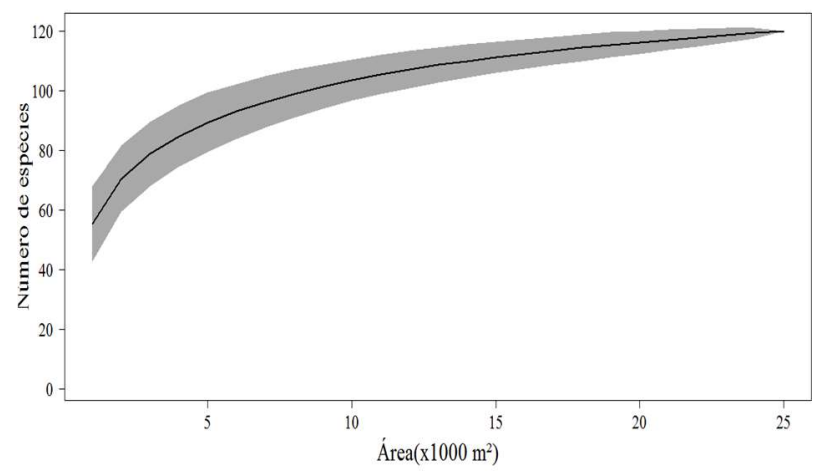

Figura 2. Curva de acumulação para um fragmento de Floresta Ombrófila Mista na Flona de Irati, estado do Paraná, Brasil.

Figure 2. Accumulation curve for a fragment of the Mixed Ombrophylous Forest in the Flona de Irati, state of Paraná, Brazil.

Constatou-se que o número de indivíduos decresceu no período monitorado, ao passo que o número de gêneros e espécies arbóreas aumentou, de 78 e 113 no ano de 2002 para
81 e 120 no ano de 2011, respectivamente, o que pode estar relacionado ao estado de conservação e estágio sucessional do fragmento em estudo. Além disso, o número de famílias botânicas manteve-se durante todo o período, com a mortalidade da família Cardiopteridaceae (2008) e o ingresso da família Asparagaceae (2011). Houve, ainda, o egresso dos indivíduos não identificados, porém estes não foram computados (Figura 3).

Merecem destaque as famílias: Myrtaceae (9 gêneros e 18 espécies), Lauraceae (5 gêneros e 14 espécies), Fabaceae (10 gêneros e 10 espécies), Salicaceae (3 gêneros e 7 espécies), Asteraceae ( 5 gêneros e 6 espécies), Sapindaceae (4 gêneros e 5 espécies), Aquifoliaceae (1 gênero e 4 espécies) e Rubiaceae (4 gêneros e 4 espécies). Essas oito famílias (19\% do total) abrangem $56,7 \%$ do número total de espécies e $72,8 \%$ do número total de indivíduos existentes no ano de 2011. Tais famílias, juntamente com a família Araucariaceae, representam $80,4 \%$ do total de indivíduos observados no fragmento.

Representadas por uma única espécie, foram encontradas vinte famílias: Anacardiaceae, Araliaceae, Araucariaceae, Arecaceae, Asparagaceae, Canellaceae, Cardiopteridaceae, Clethraceae, Elaocarpaceae, Erythroxylaceae, Loganiaceae, Lythraceae, Malvaceae, Picramniaceae, Proteaceae, Quillajaceae, Rosaceae, Simaroubaceae, Styracaceae e Theaceae.

Dentre os 84 gêneros observados durante todo o período de monitoramento do fragmento, o gênero Ocotea foi o mais representativo em termos riqueza, abrangendo 7 espécies.

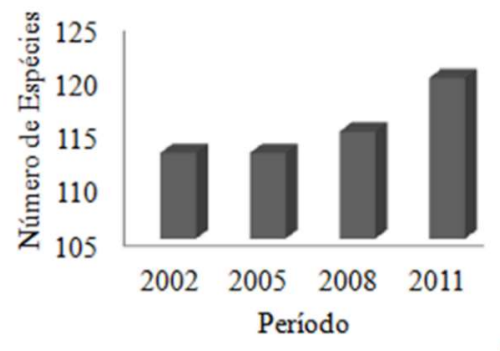

(B)

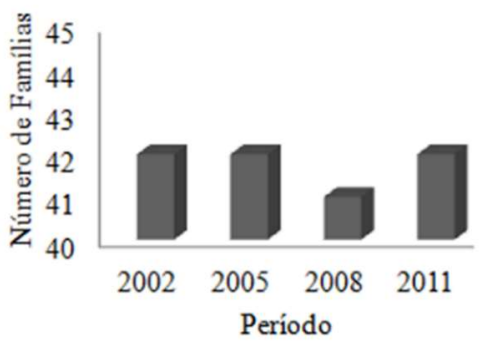

(C)

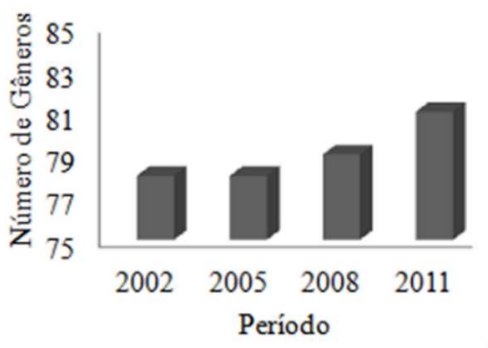

(D)

Figura 3. Evolução do número de indivíduos (A), espécies (B), famílias botânicas (C) e gêneros (D) em um fragmento de Floresta Ombrófila Mista na Floresta Nacional de Irati, Paraná, Brasil.

Figure 3. Evolution of number of individuals (A), species (B), botanical families (C) and genus (D) in a fragment of Mixed Ombrophilous Forest in the Irati National Forest, Paraná, Brazil.

Os gêneros Casearia, Eugenia, Ilex e Myrcia foram representados por 4 espécies cada; Cinnamomum, Myrciaria, Myrsine, Solanum e Symplocos, 3 espécies cada; Allophylus, Annona, Campomanesia, Cedrela, Chrysophyllum, Drimys, Maytenus, Nectandra, Piptocarpha, Vernonanthura e Zanthoxylum, 2 espécies cada. Os demais gêneros (63) apresentaram uma única espécie.
Avaliando-se a dinâmica em relação à porcentagem de espécies, em seus respectivos grupos ecológicos nos anos de 2002 e 2011, observaram-se pequenas alterações na frequência, como o aumento de $0,37 \%$ das espécies pioneiras, $1,32 \%$ das secundárias iniciais e $0,94 \%$ das espécies climácicas. Em contrapartida, as espécies pertencentes ao grupo das secundárias tardias apresentaram uma redução de 
1,75\% (Figura 4A). Em relação à porcentagem de indivíduos em seus respectivos grupos ecológicos nos anos de 2002 e 2011, observou-se o aumento de $0,15 \%$ das espécies pioneiras, $0,96 \%$ das secundárias tardias e $1,57 \%$ das espécies climácicas, ao passo que as espécies pertencentes ao grupo das secundárias iniciais apresentaram uma redução de 2,57\%, o que pode indicar um avanço sucessional do fragmento (Figura 4B).

De modo geral, a floresta se caracterizou pela presença do grupo ecológico secundário inicial, apresentando média de indivíduos, entre os anos de 2002 a 2011, igual a 48,5\% do total, seguido pelo grupo das espécies secundárias tardias $(23,5 \%)$, climácicas $(14,0 \%)$ e pioneiras $(13,8 \%)$.

As espécies com maior densidade dentro de cada grupo foram: Coussarea contracta, com 33,5\% do total de indivíduos do grupo das pioneiras; Ilex paraguariensis, totalizando 19,6\% no grupo das secundárias iniciais; Ocotea odorifera, com $39,2 \%$ do grupo das secundárias tardias e Araucaria angustifolia, com 51,6\% no grupo das espécies climácicas.
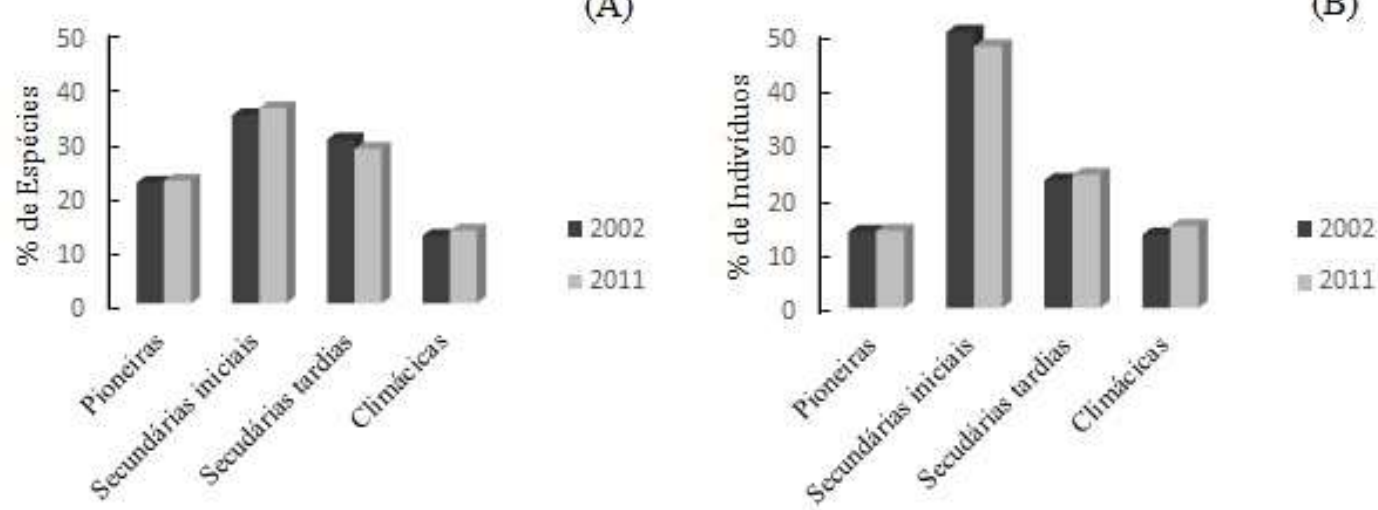

Figura 4. Frequência do número de espécies (A) e número de indivíduos (B) por grupo ecológico nos anos de 2002 e 2011, em um fragmento de FOM na Floresta Nacional de Irati, Paraná, Brasil.

Figure 4. Frequency of number of species (A) and number of individuals (B) by ecological group in years 2002 and 2011, in a fragment of FOM in the Irati National Forest, Paraná, Brazil.

\subsection{Estrutura horizontal}

De modo a reduzir o banco de informações referente à estrutura horizontal das espécies arbóreas no período 20022011 (Tabela 2), são apresentados apenas os parâmetros relativos das espécies com valor de importância (VI) superior a $1 \%$ no ano de 2011, as quais são listadas em ordem decrescente pelo VI.

Araucaria angustifolia foi a espécie de maior VI em todos os anos monitorados, seguida por Ilex paraguariensis, Ocotea odorifera, Nectandra grandiflora e Ocotea porosa. Destaca-se a importância de Araucaria angustifolia em relação à área basal do fragmento, sendo a espécie responsável por 24,6 e $26,6 \%$ de toda a área basal da floresta nos anos de 2002 e 2011 , respectivamente. É importante ressaltar que a importância da espécie ocorre, principalmente, pelo crescimento dos indivíduos já estabelecidos no local e não pelo ingresso de novos indivíduos, visto que o aumento da densidade da espécie não foi expressivo, constatando-se o ingresso de 5 indivíduos em toda a área amostrada, nos nove anos de monitoramento.

De modo geral, as espécies sofreram poucas alterações em seus valores de importância nos nove anos estudados, mesmo sendo observada a redução desse parâmetro em algumas espécies, tais como: Ilex paraguariensis, Nectandra grandiflora, Casearia decandra, Ocotea puberula, Matayba elaeagnoides, Myrsine umbellata, entre outras.

Araucaria angustifolia, Ilex paraguariensis, Ocotea odorifera, Nectandra grandiflora, Ocotea porosa, Casearia decandra, Cedrela fissilis, Nectandra megapotamica e Ocotea puberula mantiveram os maiores valores de importância anuais que, somados, correspondem a $51,4 \%$ do valor encontrado para toda a floresta, consideradas por esse motivo como as mais importantes da área estudada.

A proximidade dos valores de importância atribuída a cada espécie propiciou alterações no ordenamento das mesmas, entre os anos analisados. No entanto, Coussarea contracta foi a espécie que apresentou maior variação em relação a sua importância na estrutura horizontal da floresta, pois no ano de 2002, apresentava o $14^{\circ}$ maior valor de importância $(2,4 \%)$, ao passo que em 2011 apresentou o $10^{\circ}$ maior valor $(3,2 \%)$. A maior valoração dessa espécie em relação às demais foi devido ao seu incremento em área basal, passando de $0,26 \mathrm{~m}^{2}$.ha-1 (ano de 2002) para $0,38 \mathrm{~m}^{2} \cdot \mathrm{ha}^{-1}$ (2011) e, principalmente, a sua densidade absoluta, que passou de 19,88 indivíduos.ha ${ }^{-1}$ (2002) para 26,16 indivíduos.ha-1 (2011), sendo esta a espécie com maior densidade no grupo das pioneiras e que apresentou, dentre todas as espécies, o maior recrutamento no período, cuja taxa correspondeu a 5,5\%.

Espécies como Matayba elaeagnoides, Myrsine umbellata e Cinnamodendron dinisii tiveram redução de seus valores de importância no período avaliado, diminuindo sua representatividade na floresta. Essas espécies apresentaram ao longo do período de monitoramento do fragmento gradativa perda de densidade, dominância e frequência, onde Matayba elaeagnoides passou do $9^{\circ}$ maior valor de importância em 2002, para o $12^{\circ}$ em 2011. A espécie Myrsine umbellata, no ano de 2002 apresentava o $11^{\circ}$ maior valor de importância, em 2011 decresceu 2 posições, com redução para 28,2\% em sua densidade absoluta. Embora a migração de uma ou duas posições no ordenamento dos valores de importância de uma determinada espécie aparente ser insignificante na análise da estrutura horizontal, para espécies com elevada representatividade na floresta, podem indicar alterações significativas em sua estrutura.

Em relação ao número de espécies e famílias botânicas, os valores encontrados no presente estudo são, de maneira geral, superiores (Tabela 3) aos valores encontrados nos demais trabalhos utilizados para comparação (Figura 1). Nestes levantamentos observa-se uma grande variação na área 
amostrada e, além disso, o limite de inclusão de alguns trabalhos foi diferente, destacando os estudos realizados no estado do Rio Grande do Sul, os quais empregaram um diâmetro limite de inclusão de $9,5 \mathrm{~cm}$.

Tabela 2. Estrutura horizontal (2002-2011) das espécies com maior Valor de Importância em um fragmento de FOM na Floresta Nacional de Irati, Paraná, Brasil.

Table 2. Horizontal structure (2002-2011) of the species with the highest Importance Value in a fragment of FOM in the Irati National Forest, Paraná, Brazil.

\begin{tabular}{|c|c|c|c|c|c|c|c|c|}
\hline \multirow{2}{*}{ Espécie } & \multicolumn{2}{|c|}{ FR $(\%)$} & \multicolumn{2}{|c|}{ DR $(\%)$} & \multicolumn{2}{|c|}{$\operatorname{DoR}(\%)$} & \multicolumn{2}{|c|}{ VI $(0-100 \%)$} \\
\hline & 2002 & 2011 & 2002 & 2011 & 2002 & 2011 & 2002 & 2011 \\
\hline Araucaria angustifolia (Bertol.) Kuntze & 5,2 & 5,3 & 7,3 & 7,5 & 24,6 & 26,6 & 12,4 & 13,1 \\
\hline Ilex paraguariensis A. St.-Hil. & 5,9 & 5,7 & 10,4 & 9,3 & 5,6 & 5,0 & 7,3 & 6,7 \\
\hline Ocotea odorifera (Vell.) Rohwer & 3,8 & 4,0 & 8,9 & 9,4 & 5,2 & 5,5 & 6,0 & 6,3 \\
\hline Nectandra grandiflora Nees & 4,7 & 4,5 & 6,5 & 6,0 & 6,3 & 5,9 & 5,8 & 5,5 \\
\hline Ocotea porosa (Nees \& Mart.) Barroso & 2,9 & 2,9 & 3,3 & 3,4 & 8,7 & 9,3 & 5,0 & 5,2 \\
\hline Casearia decandra Jacq. & 4,8 & 4,6 & 6,1 & 5,6 & 2,6 & 2,5 & 4,5 & 4,2 \\
\hline Cedrela fissilis Vell. & 3,6 & 3,5 & 2,7 & 2,7 & 4,6 & 5,0 & 3,6 & 3,7 \\
\hline Nectandra megapotamica (Spreng.) Mez & 3,6 & 3,7 & 3,0 & 3,1 & 3,3 & 3,3 & 3,3 & 3,4 \\
\hline Ocotea puberula (Rich.) Nees & 3,0 & 2,8 & 2,4 & 2,3 & 5,0 & 4,7 & 3,4 & 3,3 \\
\hline Coussarea contracta (Walp.) Müll.Arg. & 2,9 & 3,6 & 3,4 & 4,7 & 0,9 & 1,3 & 2,4 & 3,2 \\
\hline Syagrus romanzoffiana (Cham.) Glassman & 3,2 & 3,3 & 3,1 & 3,2 & 2,6 & 2,5 & 3,0 & 3,0 \\
\hline Matayba elaeagnoides Radlk. & 2,9 & 2,7 & 3,1 & 2,7 & 4,1 & 3,6 & 3,4 & 3,0 \\
\hline Myrsine umbellata Mart. & 3,9 & 3,1 & 4,0 & 3,0 & 1,7 & 1,3 & 3,2 & 2,5 \\
\hline Ocotea diospyrifolia (Meisn.) Mez & 2,2 & 2,2 & 1,6 & 1,6 & 2,5 & 2,6 & 2,1 & 2,2 \\
\hline Cinnamodendron dinisii Schwacke & 2,5 & 2,3 & 2,5 & 2,1 & 2,4 & 2,0 & 2,5 & 2,2 \\
\hline Casearia sylvestris $\mathrm{Sw}$. & 1,9 & 2,3 & 2,1 & 2,6 & 0,9 & 1,1 & 1,7 & 2,0 \\
\hline Prunus myrtifolia (L.) Urb. & 3,0 & 2,5 & 2,3 & 1,8 & 1,3 & 0,9 & 2,2 & 1,7 \\
\hline Ilex theezans Mart. ex Reissek & 2,7 & 2,4 & 2,2 & 1,9 & 0,9 & 0,8 & 1,9 & 1,7 \\
\hline Myrcia hebepetala DC. & 2,0 & 2,3 & 1,6 & 2,1 & 0,5 & 0,6 & 1,4 & 1,7 \\
\hline Dalbergia brasiliensis Vogel & 2,4 & 2,2 & 1,7 & 1,6 & 1,0 & 0,9 & 1,7 & 1,6 \\
\hline Myrciaria floribunda (H.West ex Willd.) O.Berg & 1,5 & 2,1 & 1,1 & 1,7 & 0,3 & 0,5 & 1,0 & 1,4 \\
\hline Campomanesia xanthocarpa (Mart.) O.Berg & 1,6 & 1,7 & 1,0 & 1,1 & 1,0 & 1,2 & 1,2 & 1,4 \\
\hline Eugenia involucrata DC. & 1,6 & 2,0 & 1,0 & 1,4 & 0,4 & 0,6 & 1,0 & 1,3 \\
\hline Myrcia splendens (Sw.) DC. & 1,8 & 1,6 & 1,5 & 1,4 & 0,5 & 0,4 & 1,3 & 1,2 \\
\hline Psychotria vellosiana Benth. & 1,3 & 1,6 & 0,9 & 1,1 & 0,6 & 0,8 & 0,9 & 1,1 \\
\hline Allophylus edulis (A.St.-Hil. et al.) Hieron. ex Niederl. & 1,2 & 1,6 & 0,8 & 1,1 & 0,3 & 0,4 & 0,8 & 1,0 \\
\hline Subtotal 1 (espécies listadas acima) & 76,3 & 76,8 & 84,5 & 84,5 & 87,9 & 89,1 & 82,9 & 83,4 \\
\hline Subtotal 2 (demais espécies amostradas) & 23,7 & 23,2 & 15,5 & 15,5 & 12,1 & 11,0 & 17,1 & 16,6 \\
\hline Total & 100 & 100 & 100 & 100 & 100 & 100 & 100 & 100 \\
\hline
\end{tabular}

FR = Frequência Relativa (\%); DR = Densidade Relativa (\%); DoR = Dominância Relativa (\%); VI = Valor de Importância (0 - 100\%); Subtotal $1=$ corresponde as espécies com VI maior que 1\% em 2011; Subtotal 2 = corresponde as espécies com VI menor que 1\% em 2011.

Tabela 3. Resultados obtidos em trabalhos realizados na Floresta Ombrófila Mista no sul do Brasil.

Table 3. Results obtained in studies carried out in the Mixed Ombrophilous Forest in southern Brazil.

\begin{tabular}{|c|c|c|c|c|c|c|}
\hline \multirow{2}{*}{ Local } & \multicolumn{2}{|c|}{ Dados Originais } & \multicolumn{2}{|c|}{ Valor de Cobertura $>1$} & \multirow{2}{*}{$\begin{array}{c}\text { Área } \\
\text { amostrada (ha) }\end{array}$} & \multirow{2}{*}{$\begin{array}{l}\text { DAP de inclusão } \\
(\mathrm{cm})\end{array}$} \\
\hline & Espécies & Famílias & Espécies & Famílias & & \\
\hline Irati - PR ${ }^{1}$ & 124 & 42 & 32 & 17 & 25,0 & 10,0 \\
\hline São João do Triunfo - $\mathrm{PR}^{2}$ & 69 & 44 & 25 & 18 & 4,0 & 10,0 \\
\hline General Carneiro - $\mathrm{PR}^{3}$ & 39 & 31 & 29 & 17 & 0,30 & 10,0 \\
\hline Três Barras - SC ${ }^{4}$ & 72 & 29 & 21 & 16 & 26,0 & 10,0 \\
\hline São Francisco de Paula - RS & 117 & 44 & 23 & 11 & 10,0 & 9,5 \\
\hline Nova Prata - $\mathrm{RS}^{6}$ & 54 & 23 & 24 & 14 & 1,0 & 9,5 \\
\hline
\end{tabular}

1 - Presente trabalho; 2 - Durigan (1999); 3 - Watzlawick et al. (2005); 4 - Cubas et al. (2016); 5 - Ebling et al. (2014); 6 - Nascimento et al. (2001).

Com autovalor para o primeiro eixo de 0,5573 e comprimento de gradiente igual a 3,06 ( $p=0,004)$, a análise de correspondência retificada (Figura 5) evidenciou um expressivo gradiente ambiental, resultado da substituição das espécies entre os trabalhos comparados. A composição florística atual do fragmento apresenta maior riqueza de espécies quando comparada aos resultados apresentados (Tabela 3), mas com certa similaridade às áreas estudadas por Cubas et al. (2016) e Durigan (1999).

$\mathrm{O}$ resultado do teste de Mantel $(\mathrm{r}=0,7388 ; \mathrm{p}=0,01225)$ mostrou a existência de um padrão espacial, indicando que fragmentos mais próximos apresentam maior similaridade florística.

\section{DISCUSSÃO}

A maior riqueza de espécies encontrada na presente pesquisa certamente está ligada à atual fase de sucessão do fragmento, o qual foi explorado seletivamente antes da década de 1940 e não sofreu mais nenhuma intervenção, podendo ser classificada como uma floresta secundária em estágio avançado de sucessão. Da mesma forma, o tamanho da área 
amostrada é também um dos fatores que contribuíram para o aumento da riqueza.

Ao longo dos nove anos de monitoramento do fragmento detectou-se a entrada de 11 espécies no sistema. Outros autores, como Martins et al. (2017) observaram o recrutamento de duas novas espécies em um período de dois anos; Mognon et al. (2012), observaram o recrutamento de três novas espécies em um período de dez anos; Moscovich (2006) encontrou oito novas espécies em nove anos, na Floresta com Araucária de Nova Prata, a qual sofreu diferentes níveis de intervenção antrópica nesse período.

De acordo com Kersten et al. (2015), essas situações demonstram que, ao longo do desenvolvimento da sucessão florestal, há tendência ao aumento da diversidade, à diminuição de ocorrência de espécies pioneiras e ao incremento de estrutura das populações secundárias. A diminuição no número de árvores pode estar relacionada à competição (inter e intraespecífica) e ao envelhecimento das populações, e a estrutura da floresta, considerada estável (com estratos bem definidos), passa a sofrer grande influência da luminosidade.

A família Myrtaceae apresentou a maior riqueza florística, com 18 espécies. Vários trabalhos têm relatado o grande número de espécies desta família para a região fitogeográfica da Floresta com Araucária nos estados do Sul do Brasil, dentre os quais estão os de Silva et al. (2012); Higuchi et al. (2013) e Ebling et al. (2014), indicando a alta adaptabilidade dessas ao meio em questão. Para Nascimento et al. (2001), a fitofisionomia Floresta Ombrófila Mista representa um importante núcleo de dispersão da família Myrtaceae.
Dentre os estudos analisados é possível observar a complexidade das variações florísticas e estruturais entre as florestas Ombrófilas Mista do Sul do Brasil. De acordo com Figueiredo Filho et al. (2010), as variações no número de indivíduos, espécies e famílias presentes na FOM é influenciada por diversos fatores, podendo ser citados entre os mais importantes, as diferentes condições ambientais, o estágio de sucessão, diferentes amostragens entre os trabalhos comparados, entre outros. Outros fatores como a topografia, gradiente altitudinal e tipo de solo também podem influenciar a composição florística nos diferentes locais de ocorrência, visto que, embora a FOM possa parecer homogênea à primeira vista, esta é formada por múltiplas associações e agrupamentos, os quais se encontram em vários estágios de sucessão.

A maior similaridade florístico-estrutural entre os fragmentos do Paraná e Santa Catarina, em detrimento dos fragmentos do Rio Grande do Sul, observado pela análise de classificação e ordenação, pode ser atribuída ao distanciamento geográfico entre os fragmentos comparados, como verificado pelo teste de Mantel. De acordo com Ruokolainen; Tuomisto (2002), a distância geográfica pode refletir na limitação de dispersão e proporcionar mudanças na composição de espécies. Oliveira-Filho et al. (2013), verificaram que a latitude exerce papel importante nas composições florísticas da Floresta Atlântica no Sul do Brasil, havendo redução da riqueza de espécies conforme o aumento da latitude.

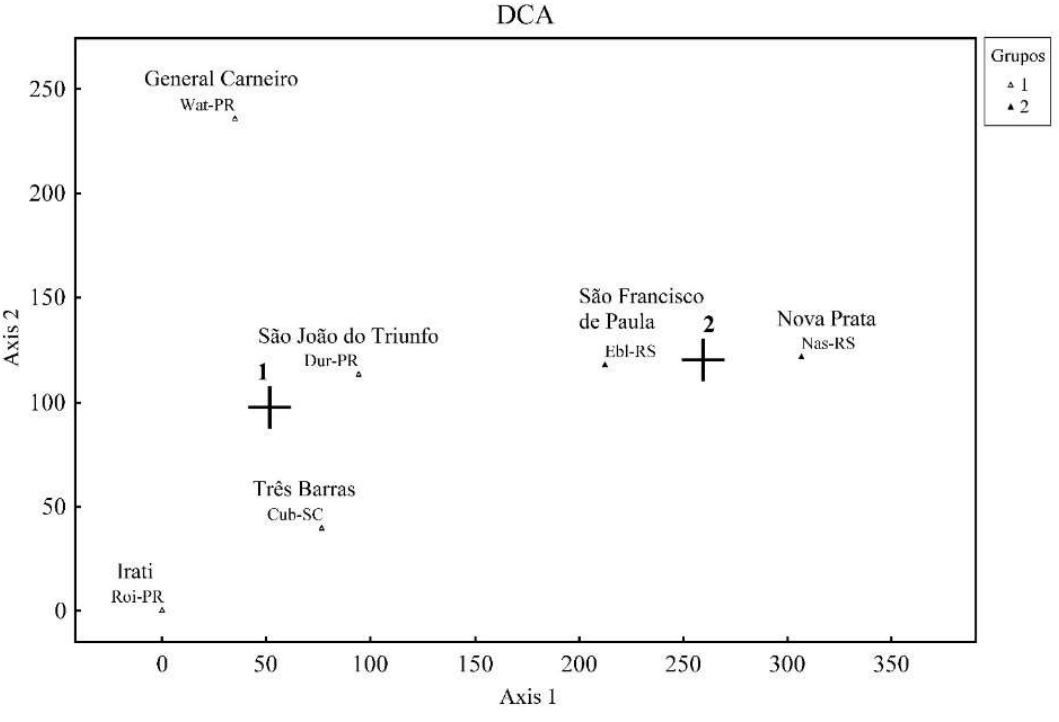

Figura 5: Análise de agrupamento (dendrograma) e análise de ordenação (Análise de Correspondência Retificada - DCA) para os estudos utilizados na comparação florístico-estrutural.

Figure 5: Cluster analysis (dendrogram) and sorting analysis (Correlated Correspondence Analysis - DCA) for the studies used in the floristicstructural comparison.

\section{CONCLUSÕES}

A floresta apresentou elevada riqueza de espécies ao longo do período de monitoramento e pequenas alterações em relação a sua composição florística e estrutura horizontal;

As diferenças florístico-estruturais entre os fragmentos utilizados para comparação com o presente estudo se devem principalmente à grande heterogeneidade intrínseca a esta fitofisionomia, como também ao aumento da dissimilaridade em função do distanciamento geográfico.

\section{REFERÊNCIAS}

APG THE ANGIOSPERM PHYLOGENY GROUP; CHASE, M. W.; CHRISTENHUSZ, M. J. M.; FAY, M. F.; BYNG, W. S.; JUDD, W. S.; SOLTIS, D. E.; MABBERLEY, D. J.; SENNIKOV, A. N.; SOLTIS, P. S.; STEVENS, P. F. An update of the Angiosperm Phylogeny Group classification for the orders and families of lowering plants: APG IV. Botanical Journal of the Linnean Society, London, v. 181, n. 1, p. 1-20, 2016. 
CARVALHO, P. E. R. Espécies arbóreas brasileiras. Brasília: Embrapa Floresta, 2003. 1 v. 1039 p.

CARVALHO, P. E. R. Espécies arbóreas brasileiras. Brasília: Embrapa Floresta, 2006. 2 v. 627 p.

CARVALHO, P. E. R. Espécies arbóreas brasileiras. v. 3. Brasília: Embrapa Floresta, 2008. v 3. 593 p.

CUBAS, R.; WATZLAWICK, L. F.; FILHO, A. F. Incremento, ingresso, mortalidade em um remanescente de Floresta Ombrófila Mista em Três Barras - SC. Ciência Florestal, Santa Maria, v. 26, n. 3, p. 889-900, 2016. DOI: http://dx.doi.org/10.5902/1980509824216

DURIGAN, M. E. Florística, dinâmica e análise proteica de uma Floresta Ombrófila Mista em São João do Triunfo, PR. 1999. 125 f. Dissertação (Mestrado) Universidade Federal do Paraná, Curitiba, Paraná.

EBLING, A. A.; GUIMARÃES, P. P.; PELISSARI, A. L.; ABRÃO, S. F.; MIRANDA, R. O. V. Alterações florísticas e estruturais em Floresta com Araucaria no estado do Rio Grande do Sul, Brasil. Agrarian Academy, Goiânia, v. 1, n. 1, p. 1-27, 2014. DOI: http://dx.doi.org/ 10.18677/Agrarian_Academy_2014_002

FIGUEIREDO FILHO, A.; DIAS, A. N.; STEPKA, T. F.; SAWCZUK, A. R. Crescimento, mortalidade, ingresso e distribuição diamétrica em fragmento de Floresta Ombrófila Mista. Floresta, Curitiba, PR, v. 40, n. 4, p. 763-776, 2010.

DOI: http://dx.doi.org/10.5380/rf.v40i4.20328

GOLDSMITH, F. B.; HARRISON, C. M. Description and analysis of vegetation. In: CHAPMAN, S.B. (Ed.). Methods in plant ecology. London: Blackwell Scientific Publications, 1976. p. 85-155.

HIGUCHI, P.; SILVA, A. C.; ALMEIDA, J. A.; BORTOLUZZI, R. L. C.; MANTOVANI, A.; FERREIRA, T. S.; SOUZA, S. T.; GOMES, J. P.; SILVA, K. M. Florística e estrutura do componente arbóreo e análise ambiental de um fragmento de Floresta Ombrófila Mista Altomontana no município de Painel, SC. Ciência Florestal, v. 23, n. 1, p. 153-164, 2013. DOI: http://dx.doi.org/10.5902/198050988449

IBGE_INSTITUTO BRASILEIRO DE GEOGRAFIA E ESTATÍSTICA. Manual Técnico da Vegetação Brasileira. 2. ed. rev. e aum. Rio de Janeiro: IBGE, 2012. $271 \mathrm{p}$.

KERSTEN, R. A.; BORGO, M.; GALVÃO, F. Floresta Ombrófila Mista: aspectos fitogeográficos, ecológicos e métodos de estudo. In: EISENLOHR, P. V.; MELO, M. M. R. F.; ANDRADE, L. A.; MEIRA NETO, A. A. (Ed.). Fitossociologia no Brasil: métodos e estudos de caso. Viçosa: UFV, 2015. p. 156-182.

LEGENDRE, P.; LEGENDRE, L. Numerical Ecology. Amsterdam: Elsevier, 2012. 853 p.

LORENZI, H. Árvores Brasileiras: Manual de Identificação e cultivos de plantas arbóreas do Brasil. 2. ed. São Paulo: Nova Odessa, 2002. 382 p.

MMA_MINISTÉRIO DO MEIO AMBIENTE. Mata atlântica: manual de adequação ambiental. Brasília, DF. SBF, 2010. $96 \mathrm{p}$.

MANTEL, N. The detection of disease clustering and a generalized regression approach. Cancer Research, Birmingham, v. 27, n. 2, p. 209-220, 1967

MARTINS, P. J.; MAZON, J. A.; MARTINKOSKI, L.; BENIN, C. C.; WATZLAWICK, L. F. Dinâmica da Vegetação Arbórea em Floresta Ombrófila Mista Montana
Antropizada. Floresta e Ambiente, Seropédica, v. 24, p. 1-12, 2017. DOI: http://dx.doi.org/10.1590/21798087.097014

MOGNON, F.; DALLAGNOL, F.; SANQUETTA, C. R.; CORTE, A. P.; MAAS, G. Uma década de dinâmica florística e fitossociológica em Floresta Ombrófila Mista Montana no sul do Paraná. Revista de Estudos Ambientais, Blumenau, v. 14, n. 1, p. 43-59, 2012.

MOSCOVICH, F. A. Dinâmica de crescimento de uma Floresta Ombrófila Mista em Nova Prata, RS. 2006. 135 f. Tese (Doutorado) - Universidade Federal de Santa Maria, Santa Maria, 2006

OLIVEIRA-FILHO, A. DKE, J. C.; JARENKOW, J. A.; EISENLOHR, P. V.; NEVES, D. R. M. Delving into the variations in tree species composition and richness across South American subtropical Atlantic and Pampean forests. Journal of Plant Ecology, v. 6, p. 1-23, 2013. DOI: https://dx.doi.org/10.1093/jpe/rtt058

OKSANEN, J.; BLANCHET, G. F.; KINDT, R.; LEGENDRE, P.; MINCHIN, P. R.; O'HARA, R. B.; SIMPSON, G. L.; SOLYMOS, P.; STEVENS, M. H. H.; WAGNER, H. Vegan: Community Ecology Package. R package version 2.4-6, 2018.

PROBIO_PROJETO DE CONSERVAÇÃO E UTILIZZAÇÃO SUSTENTÁVEL DA DIVERSIDADE BIOLÓGICA BRASILEIRA. Levantamento da Cobertura Vegetal Nativa do Bioma Mata Atlântica. Rio de Janeiro: IESB/Instituto de Geociências. 2007. 87 p. R CORE TEAM. R: A language and environment for statistical computing. R Foundation for Statistical Computing. Vienna, Austria, 2015.

ROIK, M. Dinâmica (2002-2011) e modelagem do incremento diamétrico em fragmento de Floresta Ombrófila Mista na Floresta Nacional de Irati, Paraná. 2012. 141f. Dissertação (Mestrado) - Universidade Estadual do Centro-Oeste, Irati, 2012.

RUOKOLAINEN, K.; TUOMISTO, H. Beta-diversity in tropical trees. Science, v. 297, p. 1439, 2002. DOI: https://dx.doi.org/10.1126/science.1066854

SAWCZUK, A. R.; FIGUEIREDO FILHO, A.; DIAS, A. N.; WATZLAWICK, L. F.; STEPKA, T. F. Alterações na estrutura e na diversidade florística no período 2002-2008 de uma Floresta Ombrófila Mista Montana do centro-sul do Paraná, Brasil. Floresta, Curitiba, v. 42, n. 1, p.1-10, 2012. DOI: http://dx.doi.org/10.5380/rf.v42i1.26286

SILVA, A. C.; HIGUCHI, P.; AGUIAR, M. D.; NEGRINI, M.; NETO, J. F.; HESS, A. F. (2012). Relações Florísticas e Fitossociológicas de uma Floresta Ombrófila Mista Montana secundária em Lages, Santa Catarina. Ciência Florestal, Santa Maria, v. 22, n. 1, p. 193-206. DOI: http://dx.doi.org/10.5902/198050985091

SIMEPAR, I. T. SIMEPAR. Disponível em: $<$ http://www.simepar.br/>. Acessado em 12.04.2018.

VACCARO, S. Crescimento de uma floresta estacional decidual, em três estágios sucessionais, no município de Santa Tereza, RS, Brasil. 2002. 157f. Universidade Federal de Santa Maria, Santa Maria, 2002.

WATZLAWICK, L. F.; SANQUETTA, C. R.; VALÉRIO, A. F.; SILVESTRE, R. Caracterização da composição florística e estrutural de uma Floresta Ombrófila Mista, no município de General Carneiro (PR). Ambiência, Guarapuava, v. 1, n. 2, p. 229-237, 2005. 